\title{
Influence of Activating Agents on the Adsorptive Properties of Betel nut Based Activated Carbon
}

\author{
Sahira Joshi ${ }^{1}$ and Puspa Lal Homagai ${ }^{2 *}$ \\ ${ }^{I}$ Department of Applied Sciences, Pulchowk campus, IOE, Tribhuvan University, Lalitpur, Nepal \\ ${ }^{2}$ Amrit campus, Tribhuvan University, Kathmandu, Nepal \\ Email:homagaipl@gmail.com
}

\begin{abstract}
In this study, a series of activated carbons (ACs) were prepared from Betel nut by chemical activation using $\mathrm{ZnCl}_{2}, \mathrm{H}_{3} \mathrm{PO}_{4}$ and $\mathrm{NaOH}$ as activating agents. The resultant activated carbons (ACs) were characterized by iodine number $\left(I_{N}\right)$, methylene blue number $\left(M B_{N}\right)$, surface area, scanning electron Microscopy (SEM and Fourier transform infrared spectroscopy (FTIR). The \% yield of $\mathrm{H}_{3} \mathrm{PO}_{4}$ activated carbon is higher followed by $\mathrm{ZnCl}_{2}$ and $\mathrm{NaOH}$. AC prepared by using $\mathrm{H}_{3} \mathrm{PO}_{4}$ as an activating agent showed higher iodine no., methylene blue no. and surface area of $888 \mathrm{mg} / \mathrm{gm}, 369 \mathrm{mg} / \mathrm{gm}$ and $936 \mathrm{~m}^{2} / \mathrm{gm}$ respectively. It indicated the presence of a large amount of micro and mesopores in the $\mathrm{H}_{3} \mathrm{PO}_{4}$ activated carbon. As shown by SEM micrographs, $\mathrm{H}_{3} \mathrm{PO}_{4}$ and $\mathrm{ZnCl}_{2}$ activated carbons have well developed pore structure comprising of macropores and micropores on its external surface. However their pore structure is different depending on the activating agent. Despite the different chemical activating agent used, all the prepared ACs are amorphous nature and showed similar oxygen-containing surface functional groups (carboxyl, carbonyl and phenolic groups). Among the different activating agents, $\mathrm{H}_{3} \mathrm{PO}_{4}$ seems to be best activating agents as the Betel based AC obtained by using this agent has high adsorption capacity.
\end{abstract}

Keywords: Betel nut, activated carbon, activating agents.

\section{Introduction}

Activated carbon (AC) is a porous carbonaceous material with the highly developed surface area. The characteristics of activated carbon (AC) are internal porosity and their related properties such as surface area, pore volume, pore size distribution, and the presence of surface functional groups. These properties plays key role in the adsorptive capacities of ACs. According to IUPAC, pores of AC are classified in three groups: micropores (diameter $<2) \mathrm{nm}$, mesopores $(2 \mathrm{~nm}<$ diameter $<50 \mathrm{~nm}$ ), and macropores (diameter $>50 \mathrm{~nm})^{1}$. ACs with abundance of micropores (diameters $>2 \mathrm{~nm}$ ) are used for adsorption of small molecules and highly developed mesoporous ACs are used for the adsorption of larger molecules (diameters $<2 \mathrm{~nm}$ ). Due to high adsorptive capacity, they are commonly used in various applications such as adsorption, catalyst support, gas separation and storage, solvent recovery and decolorizing, super capacitors, and as electrodes ${ }^{2}$.

AC can be prepared from carbonaceous materials by carbonization in inert atmosphere followed by activation of carbonized product. Carbonization leads to the formation of fixed carbon with rudimentary

${ }^{*}$ Corresponding author 
pore structure and activation enlarge the pores diameter and also create new pores. There is basically two methods activation: physical and chemical activation. Physical activation includes the carbonization of the raw material and the activation of the carbonized product using steam and $\mathrm{CO}_{2}$ at high temperature $\left(800-1100{ }^{\circ} \mathrm{C}\right)$. In chemical activation, the raw material is first treated with dehydrating agents such as $\mathrm{H}_{3} \mathrm{PO}_{4}, \mathrm{ZnCl}_{2}, \mathrm{KOH}, \mathrm{NaOH}, \mathrm{H}_{2} \mathrm{SO}_{4}, \mathrm{KCl}$ etc and carbonization is carried out in an inert atmosphere at relatively low temperatures $\left(400-800{ }^{\circ} \mathrm{C}\right)^{3}$. The type of chemical agent is selected as a function of the characteristics of the desired AC. Chemical activation method has several advantages over the physical activation method which includes the high surface area, relatively higher yield, lower activation temperature and shorter time needed for activating material.

The most important characteristic of an AC is its adsorption capacity which is highly influenced by the preparation conditions such as activation condition, activating agent and nature of precursor. Among these, activating agents have a great influence on the pore development and surface characteristics of the AC produced. It eliminates the impurities such as alcohol, acids, aldehyde, etc. contained in the pores during carbonization so that the pores of carbon become opened and the diameter of the pores and surface area of adsorbent increase. The most widely used activating agents are $\mathrm{ZnCl}_{2}, \mathrm{H}_{3} \mathrm{PO}_{4}, \mathrm{KOH}$ and $\mathrm{NaOH}^{4}$. $\mathrm{H}_{3} \mathrm{PO}_{4}$ and $\mathrm{ZnCl}_{2}$ are used for the activation of lignocellulosic materials, which have not been carbonized previously; whereas $\mathrm{NaOH}$ and $\mathrm{KOH}$ are used for the activation of coal precursors or chars 5 .

In the last decades, the use of alternative precursors from industrial wastes and agricultural byproducts has gained importance because of the abundant supply at no or low costs. These agricultural materials include corncob ${ }^{6}$, cherry stone ${ }^{7}$, bamboo $^{8}$, coconut shell ${ }^{9}$ etc. Betel nut or Areca nut is the seed of the oriental palm Areca catechu Linnaeus. Betel nut contains cellulose, hemicellulose, lignin alkaloids and Tanins generally required for the production of porous carbon materials. In the present study, Betel (Areca catechu) nut were selected as precursor for preparation of AC because of their wide availability in South East Asia. The aim of the present work was to study influence of activating agents on the adsorptive properties of Betel nut derived AC.

\section{Experimental Methods}

\section{Materials}

The Betel nuts were purchased from local market, Kathmandu, Nepal. The chemicals used for this investigation and analysis were all analytical grade. Ultra high pure (UHP) nitrogen was used for inert atmosphere during carbonization. Betel nuts were washed with distilled water and dried in an air oven at $110^{\circ} \mathrm{C}$ for $24 \mathrm{hrs}$ and then crushed into powder. The nut powder was then sieved to obtain the fraction of size $212 \mu \mathrm{m}$.

\section{Preparation of activated carbon}

20 gm of dried, crushed Betel nut powder was separately mixed with $\mathrm{H}_{3} \mathrm{PO}_{4}, \mathrm{ZnCl}_{2}$ and $\mathrm{NaOH}$ in the ratio of $1: 1$ by weight. Then, the mixtures were stirred with glass rod at $70^{\circ} \mathrm{C}$ until completely dried. Then, samples were dried in an oven at $110^{\circ} \mathrm{C}$ for 24 hours. The dried samples were separatively carbonized in a horizontal tubular furnace at $400^{\circ} \mathrm{C}$ under a continuous nitrogen flow of nitrogen $(75$ $\mathrm{ml} / \mathrm{min}$ ) for $3 \mathrm{hrs}$. The resultant ACs were treated with $1 \% \mathrm{NaHCO}_{3}$ solution (in case of activating agent $\mathrm{H}_{3} \mathrm{PO}_{4}$ ), and $\mathrm{HCl}$ solution (in case of activating agent $\mathrm{NaOH}$ ). The carbon was subsequently washed with 
warm distilled water until the $\mathrm{pH}$ of washing became neutral. The sample was then dried at $110^{\circ} \mathrm{C}$ for 24 hrs and sieved to get the particles of size $106 \mu \mathrm{m}$. This AC was stored for further use.

\section{Characterization of activated carbon}

Iodine number of ACs was determined according to ASTM D4607-94 method ${ }^{10}$. Methylene blue number of ACs was determined by single point adsorption isotherm studies according to Standard Method $^{11}$. Surface area of AC was estimated by iodine and methylene blue numbers using multiple regressions $^{12}$. Surface functional group of the ACs was identified using Fourier Transform-Infrared (FTIR) spectroscopy. FTIR spectra were recorded between 4000 and $400 \mathrm{~cm}^{-1}$ on a Nicolet 4700 FTIR (Thermo Electron Corporation). The surface morphology was studied by scanning electron microscope (SEM) Hitachi S-4800. Structural analysis was carried out by powder X-ray diffraction (XRD) using Rigaku MiniFlexII-C system with $\mathrm{CuK} \alpha(\lambda=1.54056 \AA)$ radiation at a scanning rate of $1^{\circ} \mathrm{min}^{-1}$.

\section{Results and Discussion}

\section{Yield of the activated carbon}

The percentage yield of Betel nut ACs using different activating agents is shown in Table 1.

Table-1: The percentage yield of Betel nut ACs using different activating agents

\begin{tabular}{|l|l|}
\hline Activated carbon & Yield (\%) \\
\hline $\mathrm{NaOH}$ activated carbon & 18 \\
\hline $\mathrm{ZnCl}_{2}$ activated carbon & 28 \\
\hline $\mathrm{H}_{3} \mathrm{PO}_{4}$ activated carbon & 32 \\
\hline
\end{tabular}

The results showed that \% yield of $\mathrm{H}_{3} \mathrm{PO}_{4}$ activated carbon is higher followed by $\mathrm{ZnCl}_{2}$ and $\mathrm{NaOH}$. It may be because $\mathrm{H}_{3} \mathrm{PO}_{4}$ promotes depolymerization, dehydration, and redistribution of constituent biopolymers. It favors the conversion of aliphatic to aromatic compounds. It increases the yield of AC. In case of $\mathrm{ZnCl}_{2}$ activation, $\mathrm{ZnCl}_{2}$ as a Lewis acid and enhances the aromatic condensation and polymerization reactions of the carbon structure. As a result, the volatile molecules are stabilized and increased the carbon yield. The lower percentage yield of $\mathrm{NaOH}$ activated carbon is due to the intercalation of the metallic sodium to the carbon matrix. It results in the decrease of the yield of the $\mathrm{AC}^{13}$. Hence, it confirms that, activating agent notably affect the yield of AC. Similar result was observed in the AC produced by Rubber seed pericarp using Microwave-Induced different chemical activating agent ${ }^{14}$.

\section{Iodine Number and methylene blue number}

Adsorption of iodine and methylene blue dye from aqueous solution is considered a simple and quick test for evaluating the approximate surface area of ACs. Iodine number is the milligrams of iodine adsorbed by $1 \mathrm{gm}$ of carbon ${ }^{12}$. Iodine is a small molecule with minimum pore diameter $10 \AA$ whereas methylene blue is a medium size molecule with minimum pore diameter $15 \AA$. Iodine number can be correlated with ability of adsorbent to adsorb low molecular weight substances so it indicates the microporosity of AC. Methylene blue number is defined as the milligram of methylene blue adsorbed onto 1 gm of carbon ${ }^{11}$. Methylene blue number indicates ability of adsorbing high molecular weight substances 
indicating the meso-porosity ${ }^{15}$. Iodine no., methylene blue no. and surface area of Betel nut ACs prepared by using different activating agents are presented in Figure: 1.

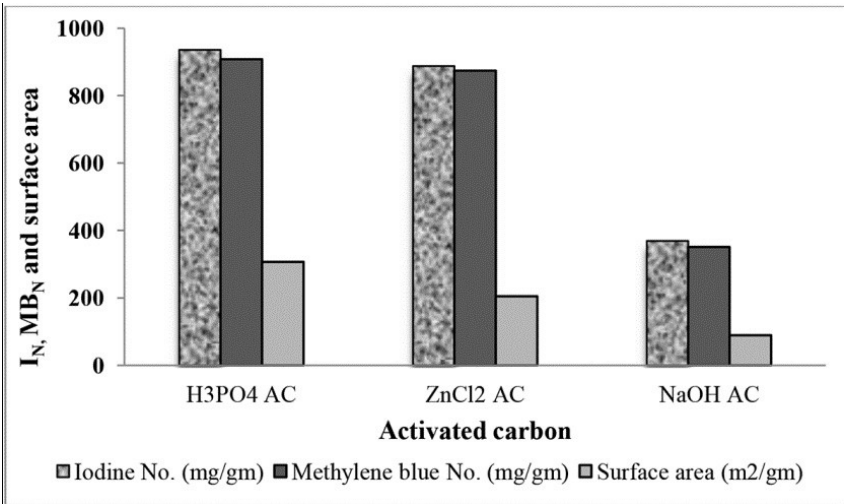

Figure 1: Iodine no., methylene blue no. and surface area of Betel nut ACs using different activating agents

Iodine no., methylene blue no. and surface area of the $\mathrm{H}_{3} \mathrm{PO}_{4}$ activated carbon is much higher when compared to $\mathrm{ZnCl}_{2}$ and $\mathrm{NaOH}$ activated carbon. Thus, it indicates that, both $\mathrm{H}_{3} \mathrm{PO}_{4}$ activated carbon led to the most micro and meso-porous material with high surface area. The micro, meso-porosity and surface area increased in the order of $\mathrm{H}_{3} \mathrm{PO}_{4} \mathrm{AC}>\mathrm{ZnCl}_{2} \mathrm{AC}>\mathrm{NaOH}$ AC. The variation in micro and mesoporosity of these ACs might have resulted in the differences in their reactivity with the different activating agents which in turn are related to the different activation mechanism. The differences among the effect of each of these activating agents is that, $\mathrm{NaOH}$ produces only widens the microporosity diameter, while $\mathrm{ZnCl}_{2}$ develops both wide micropores and small mesopores. $\mathrm{H}_{3} \mathrm{PO}_{4}$ forms large mesopores and even macropores ${ }^{16}$. Hence, the results indicate that the activating agent has a significant effect in the pore structure of Betel nut AC which directly correlates to the adsorption capacity of the AC.

\section{SEM Images}

These SEM images are primarily used to observe surface morphology and topography of AC. It also exhibits the nature and size of the pore, depending on the magnification of the image taken. SEM micrographs of Betel nut ACs prepared by using different activating agents are presented in Figure 2.

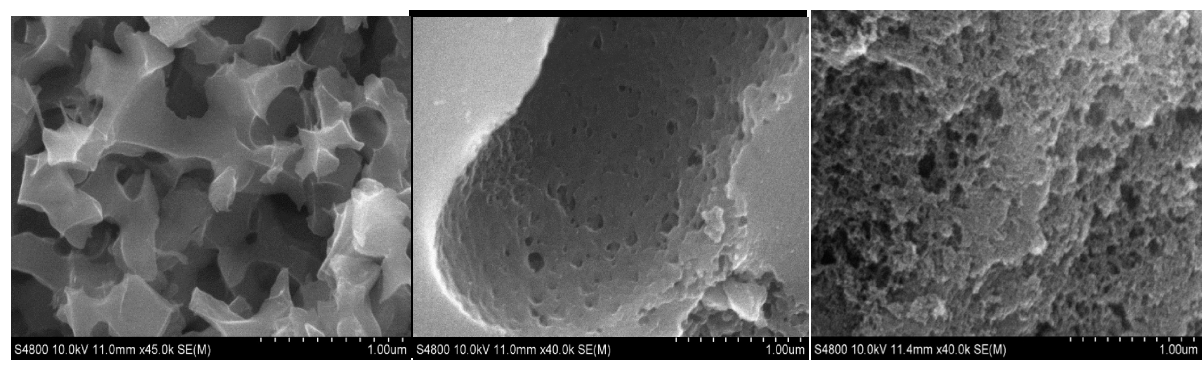
(A) $\mathrm{NaOH}$ activated carbon
(B) $\mathrm{ZnCl}_{2}$ activated carbon
(C) $\mathrm{H}_{3} \mathrm{PO}_{4}$ activated carbon

Figure 2: SEM micrographs of AC using different activating agents

As shown in Fig. 2, the scanning electron micrographs (SEM) of the surface morphology of the carbon prepared from different activating agents are compared. The external surface of $\mathrm{NaOH}$ activated 


\section{J. Nepal Chem. Soc., Vol. 37, 2017}

carbon (Figure: 2 A) shows the formation of large macropore structure without any mesopores. $\mathrm{ZnCl}_{2}$ activated carbon shows well developed porosity (Figure: $\mathbf{2}$ B). However, mesopores structure is not fully developed. On the other hand, external surface of $\mathrm{H}_{3} \mathrm{PO}_{4}$ activated carbon (Figure: 2 C) exhibits heterogeneous distribution of fine mesopores. During carbonization, activating agents gets evaporated leaving the space previously occupied by the reagents that results in formation of the pores and cavities on the surface of the AC. These pores can act as channels to the micro-porous network which increases the surface area for adsorption. The mechanisms of chemical activation using these activating agents are quite different. The mechanism by which $\mathrm{NaOH}$ activates involves the disintegration of structure following intercatalation as well as some gasification by oxygen molecules of hydroxide. $\mathrm{ZnCl}_{2}$ activation promotes the extraction of water molecules from the lignocellulosic structures which leads to the generation of porosity. The activation mechanism with $\mathrm{H}_{3} \mathrm{PO}_{4}$ involves promoting bond cleavage reactions and formation of cross-links by acid catalysis ${ }^{16}$. Iodine and methylene blue no. also supported this result. Hence, the activating agent influenced the topographical characteristics of the Betel nut based carbon surfaces.

\section{Fourier Transform Infrared (FTIR) Spectra}

Adsorption capacity of $\mathrm{AC}$ is determined by porosity, as well as the functional group present on the surface. Among various surface functional groups, the oxygen/nitrogen-containing group was found to play a critical role in the uptake of polar compounds. FTIR spectra of the Betel nut ACs prepared by using different activating agents are presented in Figure: 3.

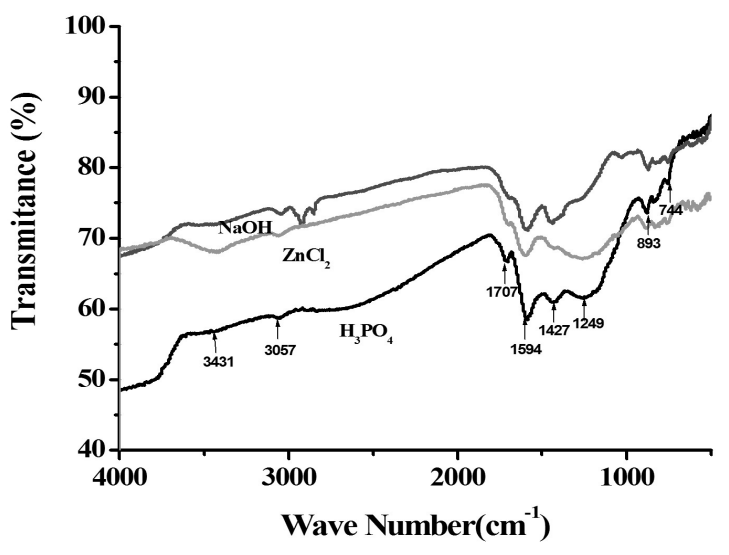

Figure 3: FTIR spectra of Betel nut ACs using different activating agents

The spectra of all the $\mathrm{AC}$ samples derived from Betel nut with $\mathrm{H}_{3} \mathrm{PO}_{4}, \mathrm{ZnCl}_{2}$, and $\mathrm{NaOH}$ have many similar features. The FTIR spectra exhibit a broad band around $3431 \mathrm{~cm}^{-1}$ which can be attributed to $-\mathrm{OH}$ functional groups of phenol, alcohol, and carboxylic acid ${ }^{17}$. Absorption peaks slightly above $3057 \mathrm{~cm}^{-1}$ in $\mathrm{AC}$ corresponds to the stretching vibration of $\mathrm{C}=\mathrm{C}$ unsaturated Alkenes ${ }^{18}$. The band located at 1707 $\mathrm{cm}^{-1}$ is corresponds to the stretching vibration of $\mathrm{C}=\mathrm{O}$ in ketones, aldehyde, lactone, and carboxyl ${ }^{13}$. The band around $1594 \mathrm{~cm}^{-1}$ and $1427 \mathrm{~cm}^{-1}$ are associated with $\mathrm{C}=\mathrm{C}$ stretching in aromatic rings found on the lignin structure ${ }^{19}$. Similarly, the peaks around $1249 \mathrm{~cm}^{-1}$ may be attributed to the $\mathrm{C}-\mathrm{O}$ stretching bands of ethers, phenol or lactones ${ }^{5}$. Weak peaks in the region of $893-744 \mathrm{~cm}^{-1}$ in FTIR spectra indicate C-H out- 
of-plane bending in the aromatic rings. From the FTIR data, It can thus be concluded that that all the ACs contain oxygenated functional groups such as $-\mathrm{OH},>\mathrm{C}-\mathrm{O}, \mathrm{COOH}$, and lactones. Similar results were observed in the activated Lapsi seed stone carbon ${ }^{20}$. It seems that the activating agents such as $\mathrm{H}_{3} \mathrm{PO}_{4}$, $\mathrm{ZnCl}_{2}$ and $\mathrm{NaOH}$ do not have much influence on the type of oxygenated surface functional groups.

\section{$\mathrm{X}$-ray diffraction}

XRD is the useful method to show the crystalline and amorphous materials. X-ray diffraction pattern of Betel nut ACs prepared by using different activating agents is presented in Figure.4.

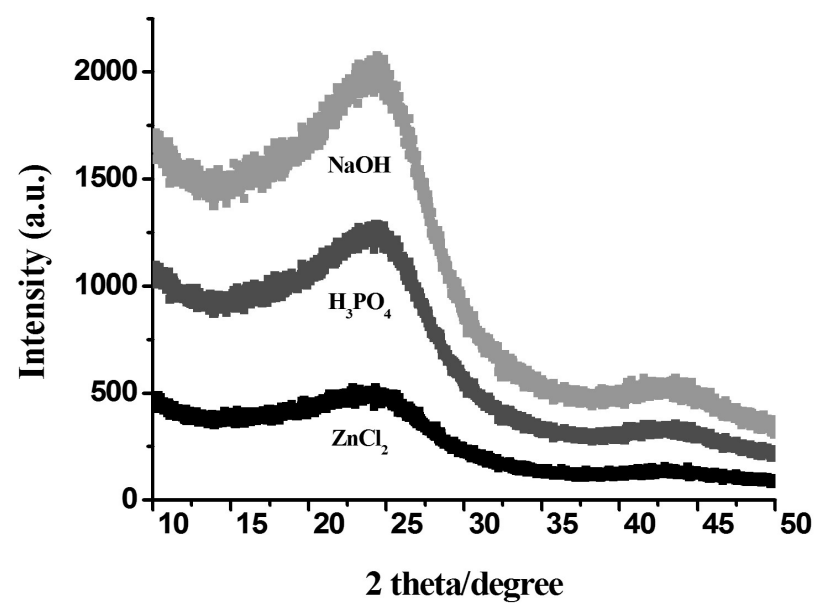

Figure 4: X-ray diffraction pattern of Betel nut ACs using different activating agents

Figure: 4 shows XRD patterns of ACs prepared from Betel nut using different activating agents. XRD patterns of all the samples shows one broad (at diffraction angle of about $25^{\circ}$ ) and one weak diffraction peak (at diffraction angle of about $43^{\circ}$ ) corresponding to the (002) and (100) planes of graphitic clusters. The peak intensities are relatively weak, indicating that the graphitic structures are not fully developed. Several researchers reported that AC to be amorphous materials (Khalil et al., 2013). From the results, it is indicated that, activating agents does not make any considerable differences crystalline structure of AC.

\section{Conclusions}

High surface areas ACs were prepared by chemical activation Betel nut powder with $\mathrm{H}_{3} \mathrm{PO}_{4}$ at $400{ }^{\circ} \mathrm{C}$. As shown by SEM image, $\mathrm{ZnCl}_{2}$ mostly forms micropores in the carbon network, while phosphoric acid forms both micro- and mesopores. $\mathrm{NaOH}$ activation results microporous carbon which is may be due to the destruction of the cellulose structure caused by the $\mathrm{NaOH}$ activation. FTIR analysis shows that all the ACs are rich in oxygenated surface functional groups and are crystalline in structure. Among the various activating agents, $\mathrm{H}_{3} \mathrm{PO}_{4}$ is better activating agent for the preparation of $\mathrm{AC}$ from Betel nut.

\section{Acknowledgements}




\section{J. Nepal Chem. Soc., Vol. 37, 2017}

The authors would like to express sincere gratitude to Prof. Dr. Raja Ram Pradhananga, Central Department of Chemistry, Tribhuvan University, Nepal for his support and constructive suggestions throughout the research work. The authors gratefully acknowledges the University Grants Commission for funding this research work.

\section{References}

1. IUPAC, Appendix II, Colloid and Surface Chemistry, Pure Appl. Chem., 1972, 31(4), 578.

2. A. Kumar and H. MohanJena, Res. Phys., 2016, 6, 651-658.

3. Joshi S., Shrestha L.K., Kamachi Y., Yamauchi Y., Pradhananga M.A., Pokharel B.P., Ariga K., and Pradhananga R.R., J Nanosci Nanotechnol, 2014, 14, 1-8.

4. T. E. Rufford, J. Zhu and D. Hulicova-Jurcakova, Pan Stanford Publishing Pte Ltd, ISBN-10 9814411132, 2014.

5. S.M. Yakout and G. Sharaf El-Deen, Arab j.Chem., 2016, 9(2), S1155-S1162.

6. G.O. El-Sayed, M.M. Yehia, and A.A. Asaad, Water Resources and Industry, 2014, 7(8), 66-75.

7. M.O. Marin, J.A. Fernandez, M.J Lazaro., C. Fernandez-Gonzalez, A. Macias-Garcia, V.GomezSerrano, F. Stoeckli and T.A. Centeno, Mater. Chem. Phys, 2009. 114, 323-327.

8. Q.S. Liu, T. Zheng, P. Wang and L. Guo, Industrial Crops and Products, 2010, 31, 233-238.

9. W.M.A.W. Daud and W.S.W. Ali, Bioresour Technol., 2004, 93, 63-69.

10. Standard Test Method for Determination of Iodine Number of Activated Carbon, 2006, ASTM D4607-94.

11. F. Raposo, M.A. De La Rubia and R. Borja, J. Hazard. Mater., 2009, 165, 291-299.

12. Cleiton, N. A. and Guerreiro, M. C. Quim Nova, 2011, 34(3), 472-476.

13. Prahas D, Kartika Y, Indraswati N, Ismadji S., Chem Eng J., 2008, 140, 32-42.

14. D. Anis, M.A.M. Ishak, A.G. Zaidi, I. Khudzir, M.N. Iqbaldin, Uwaisulqarni M. Osman, W.I. Nawawi, int. j. sci. res. publ., 2014, 4 (7), ISSN 2250-3153.

15. Malik R., Ramteke D.S. and Wate S.R., Indian J. Chem. Technol., 2006, 13, 319-328.

16. M. Molina-Sabio and F. Rodriguez-Reinoso, Colloids Surf A Physicochem Eng Asp., 2004, 241 15-25.

17. Z. Al-Qodah and R. Shawabkah, Braz. J. Chem. Eng, 2009, 26, 1.

18. Rajbhandari R., Shrestha L. K., Pokharel B. P. and Pradhananga R. R., J Nanosci Nanotechnol, 2013, 13(4), 2613-2623.

19. Sricharoenchaikul V., Pechyen C, Ahtong D., and Atong D., American Chemical Society, 2008.

20. S. Joshi, M. A, Pradhananga, B. P. Pokharel and R. R. Pradhananga, Res. j. chem. sci., 2013, 3(5), 19-24.

21. H.P.S. Khalil, Abdul, M. Jawaid, P. Firoozian, Rashid, Umer; Islam, Aminul; Akil, Hazizan Md., J Biobased Mater Bio, 2013, 7(6), 708-714. 